\title{
Evidence for climate-driven synchrony of marine and terrestrial ecosystems in northwest Australia
}

\author{
JOYCE J.L. ONG ${ }^{1,2}$, ADAM N. ROUNTREY ${ }^{3}$, JENS ZINKE ${ }^{4,5,6}$, JESSICA J. MEEUWIG ${ }^{1}$, \\ PAULINE F. GRIERSON 7 , ALISON J. O'DONNELL ${ }^{7}$, STEPHEN J. NEWMAN ${ }^{8}$, \\ JANICE M. LOUGH ${ }^{5}$, MÉLISSA TROUGAN ${ }^{9}$ and MARK G. MEEKAN ${ }^{2}$ \\ ${ }^{1}$ Center for Marine Futures, School of Animal Biology, The University of Western Australia Oceans Institute (M096), 35 Stirling \\ Highway, Crawley, WA 6009, Australia, ${ }^{2}$ Australian Institute of Marine Science, UWA Oceans Institute (M096), 35 Stirling \\ Highway, Crawley, WA 6009, Australia, ${ }^{3}$ Museum of Paleontology, University of Michigan, 1109 Geddes Avenue, Ann Arbor, MI \\ 48109-1079, USA, ${ }^{4}$ Department of Environment and Agriculture, Curtin University of Technology, Perth, WA 6845, Australia, \\ ${ }^{5}$ Australian Institute of Marine Science, PMB 3 Townsville MC, Townsville, Qld 4810, Australia, ${ }^{6}$ School of Geography, \\ Archaeology and Environmental Studies, University of Witwatersrand, 1 Jan Smuts Avenue, Braamfontein 2000, Johannesburg, \\ South Africa, ${ }^{7}$ Ecosystems Research Group, School of Plant Biology, The University of Western Australia (M090), 35 Stirling \\ Highway, Crawley, WA 6009, Australia, ${ }^{8}$ Western Australian Fisheries and Marine Research Laboratories, Department of \\ Fisheries, Government of Western Australia, P.O. Box 20, North Beach, WA 6920, Australia, ${ }^{9}$ Natural Marine Park of Mayotte, \\ Dembeni 97660 , France
}

\begin{abstract}
The effects of climate change are difficult to predict for many marine species because little is known of their response to climate variations in the past. However, long-term chronologies of growth, a variable that integrates multiple physical and biological factors, are now available for several marine taxa. These allow us to search for climate-driven synchrony in growth across multiple taxa and ecosystems, identifying the key processes driving biological responses at very large spatial scales. We hypothesized that in northwest (NW) Australia, a region that is predicted to be strongly influenced by climate change, the El Niño Southern Oscillation (ENSO) phenomenon would be an important factor influencing the growth patterns of organisms in both marine and terrestrial environments. To test this idea, we analyzed existing growth chronologies of the marine fish Lutjanus argentimaculatus, the coral Porites spp. and the tree Callitris columellaris and developed a new chronology for another marine fish, Lethrinus nebulosus. Principal components analysis and linear model selection showed evidence of ENSO-driven synchrony in growth among all four taxa at interannual time scales, the first such result for the Southern Hemisphere. Rainfall, sea surface temperatures, and sea surface salinities, which are linked to the ENSO system, influenced the annual growth of fishes, trees, and corals. All four taxa had negative relationships with the Niño-4 index (a measure of ENSO status), with positive growth patterns occurring during strong La Niña years. This finding implies that future changes in the strength and frequency of ENSO events are likely to have major consequences for both marine and terrestrial taxa. Strong similarities in the growth patterns of fish and trees offer the possibility of using tree-ring chronologies, which span longer time periods than those of fish, to aid understanding of both historical and future responses of fish populations to climate variation.
\end{abstract}

Keywords: Callitris columellaris, coral core, El Niño Southern Oscillation, environmental drivers of growth, growth chronology, Lethrinus nebulosus, Lutjanus argentimaculatus, otolith, Porites spp., tree-ring

Received 23 January 2016; revised version received 23 January 2016 and accepted 25 January 2016

\section{Introduction}

Research efforts that focused on the effects of climate change on organisms in both terrestrial and marine ecosystems (Rosenzweig et al., 2008; Hoegh-Guldberg \& Bruno, 2010) have mostly examined single species or groups of species in common environments. Although it is recognized that terrestrial and marine ecosystems are intimately linked (e.g., Dai \& Wigley, 2000), the isolated nature of many studies means that the effects of a

Correspondence: Joyce Ong, tel. +618 63694081, fax +618 64884585, e-mail: joyce.ong@research.uwa.edu.au climate phenomenon across different ecosystems have not been fully explored. Our understanding of these connections has been further hampered by a lack of long-term (decades to centuries) records of the responses of marine taxa to climate variations (Rosenzweig et al., 2008; Richardson et al., 2012). Chronologies of growth are now being developed for an expanding suite of marine organisms including corals, molluscs, and fishes, all of which have annual cycles of growth within their hard parts (see review by Morrongiello et al., 2012). These chronologies provide powerful insights into the effects of climate change, since growth 
is a variable that integrates the effects of multiple physical and biological factors (Morrongiello et al., 2012) and these taxa are relatively long-lived (typically many decades).

Initial attempts to compare growth of taxa across ecosystems have shown evidence for links between oceanic/atmospheric variation and growth, with some studies revealing climate-driven synchrony in growth across multiple taxa. For example, the growth of freshwater fish and trees were correlated in United States because of similar responses of these taxa to rainfall and river discharge (Guyette \& Rabeni, 1995). Synchronous growth patterns of trees, marine fish, and bivalves in the northeast Pacific have been linked to El Niño Southern Oscillation (ENSO) through the influence this phenomenon has on sea surface temperatures (SST), land temperatures, and precipitation (Black et al., 2009). An understanding of the factors and mechanisms that drive such linkages provides us with an improved capacity to hind- and forecast the effects of climate change on the growth of aquatic organisms.

Additionally, growth chronologies derived from taxa that are sensitive to climate variations can be utilized to reconstruct past patterns of climate. In Australia, longterm (multi-decadal) growth records from trees and corals have been used to extend records of rainfall (e.g., Cullen \& Grierson, 2009; Lough, 2011; O'Donnell et al., 2015) and SST (Hendy et al., 2002; Zinke et al., 2014, 2015) to times prior to instrumental records. Where connections between ocean and atmospheric processes lead to synchronous growth responses among marine and terrestrial taxa, multiproxy reconstructions of broad-scale climate phenomena can be developed. For example, tree and coral growth increments and ice core stratigraphy spanning the Pacific basin have been found to be synchronously responsive to the influence of the ENSO phenomenon on regional temperatures and precipitation. These chronologies were subsequently used to develop a robust, multiproxy reconstruction of ENSO variability over the last $\sim 450$ years (Braganza et al., 2009). Such reconstructions have greatly extended instrument records and furthered our knowledge of the amplitude and frequency of variation in climate through time.

Linked biological responses of taxa across terrestrial and marine ecosystems could also enable the use of terrestrial chronologies (which are generally available over longer time scales than marine records) as proxies for estimating the likely responses of marine taxa to climate change. For example, synchrony in the growth of trees, marine fish, and the breeding success of seabirds has been linked to the influence of sea level pressure on upwelling and precipitation in the northeast Pacific (Black et al., 2014). This strong connection between oceanic and atmospheric processes has enabled the use of growth chronologies from trees to develop a robust 600-year reconstruction of upwelling intensity (California Current Winter Index) along the California coast (Black et al., 2014). Similarly, other coastal ecosystems with strong links to atmospheric processes that influence trees may benefit from this method of hindcasting historic ecosystem states beyond available instrumental records.

Here, we present the first regional comparison of the climatic drivers of the growth of fishes, corals, and trees from the Southern Hemisphere. We focus on the marine and terrestrial environments of northwest (NW) Australia. Western Australia (WA) has been identified as a potential 'hotspot' of climate change (Pearce \& Feng, 2007), where water temperatures along the NW coast are predicted to increase by more than $2{ }^{\circ} \mathrm{C}$ by the year 2055 (Cheung et al., 2012). In this region, large-scale drivers (i.e., over hundreds to thousands of kilometers) such as the ENSO interact with regional Indian Ocean processes to influence the marine environment on the NW coast (Marshall et al., 2015; Zinke et al., 2015). The combination of these interactions can result in phenomena such as the 'Ningaloo Niño', an anomalous warming of surface waters that has caused widespread fish kills and coral bleaching (Feng et al., 2013).

Long-term growth chronologies have already been developed from trees ( $\mathrm{O}^{\prime}$ Donnell et al., 2015), corals (Cooper et al., 2012), and fish (Ong et al., 2015) in this region, providing an opportunity to investigate linked biological responses to climate patterns across taxa and ecosystems. These earlier studies have revealed that growth of trees in NW Australia show a strong positive response to rainfall because water is a limiting resource (O'Donnell et al., 2015). Similarly, coral growth is influenced by regional changes in SST that affect calcification rates (Cooper et al., 2012), while adult fish respond to changes in SST and sea surface salinity (SSS) because of changes in metabolism rates, osmoregulation, or food conversion efficiencies (Ong et al., 2015). Given that ENSO drives regional environmental and climate variables such as SST, SSS, and rainfall in Australia's NW region, we hypothesized that the growth of these taxa will exhibit similar patterns. Additionally, we identify the key environmental variables driving patterns in growth among taxa.

\section{Materials and methods}

\section{Environmental drivers of marine and terrestrial regions in Western Australia}

The NW coast of Australia includes two major marine bioregions (as defined by Fletcher \& Santoro, 2014): the North 
Coast, which includes coastal areas of the Pilbara and Kimberley regions, and the more southerly Gascoyne Coast from Exmouth Gulf to Shark Bay (Fig. 1). The warm, low salinity waters off the North Coast are of Pacific origin, entering the region via the Indonesian through-flow and interacting with waters of the Indian Ocean (Meyers, 1996). The North Coast bioregion is entirely tropical while the Gascoyne Coast bioregion is subtropical and is a transition zone between the tropics to the north and the temperate zone to the south (Fletcher \& Santoro, 2014). The marine environment off the Gascoyne Coast is influenced by the Leeuwin Current, a pole-ward flowing, eastern boundary current (Cresswell \& Golding, 1980; Feng et al., 2009) that transports warm tropical waters southwards along the coast of WA (Fletcher \& Santoro, 2014) and is strongly influenced by ENSO on interannual time scales (Feng et al., 2009). In the tropical marine waters of the North Coast, SST in summer averages $28.8{ }^{\circ} \mathrm{C}$ with a maximum of ca. $30{ }^{\circ} \mathrm{C}$ while average SST in winter drops to a monthly minimum of ca. $24{ }^{\circ} \mathrm{C}$ (1970-2010 seasonal averages; Rayner et al., 2003). In this region, the intraannual variability of SSS is low, with an average of 34.8 practical salinity units (PSU) and a range of 0.3 PSU (1970-2010 seasonal average; Good et al., 2013). In the Gascoyne Coast region, average SST in summer is slightly lower than the North Coast $\left(25.2^{\circ} \mathrm{C}\right.$; range of $\left.\sim 1.1^{\circ} \mathrm{C}\right)$ while SSS is slightly higher with an average of 35.4 PSU and range of 0.3 PSU. Both the North Coast and the Gascoyne Coast are seasonally influenced by summer tropical cyclones (Fletcher \&
Santoro, 2014) and the Kimberley region of the North Coast, in particular, is affected by river outflows from summer rainfall (Lough, 1998).

In the semiarid and arid terrestrial environments of NW Australia, biological processes are principally driven by rainfall (Cullen et al., 2008). This is shown by strong correlations of the growth of Callitris columellaris trees with rainfall and humidity (Cullen \& Grierson, 2007; Cullen et al., 2008; O'Donnell et al., 2015). In NW Australia, rainfall is extremely variable both within and among years. Most rain falls during the summer months (average of $102 \mathrm{~mm}$ per month from January to March over the years 1970-2010; Jones \& Harris, 2008) and is associated with tropical cyclones or rain-bearing low pressure systems (Gentilli, 1971). In contrast, the austral winter to spring months of June to November average only $12 \mathrm{~mm}$ per month (data from 1970 to 2010; Jones \& Harris, 2008).

\section{Growth chronologies}

Growth chronologies from Lutjanus argentimaculatus, Porites spp. and C. columellaris were obtained from earlier studies as mentioned above (see Supplementary Table S1 for details on the type of data, length of chronology, location, and source). These were supplemented with a new growth chronology developed from otoliths of another tropical fish, the spangled emperor (Lethrinus nebulosus). For all species, we only used data for the years 1984-2003, which were common to

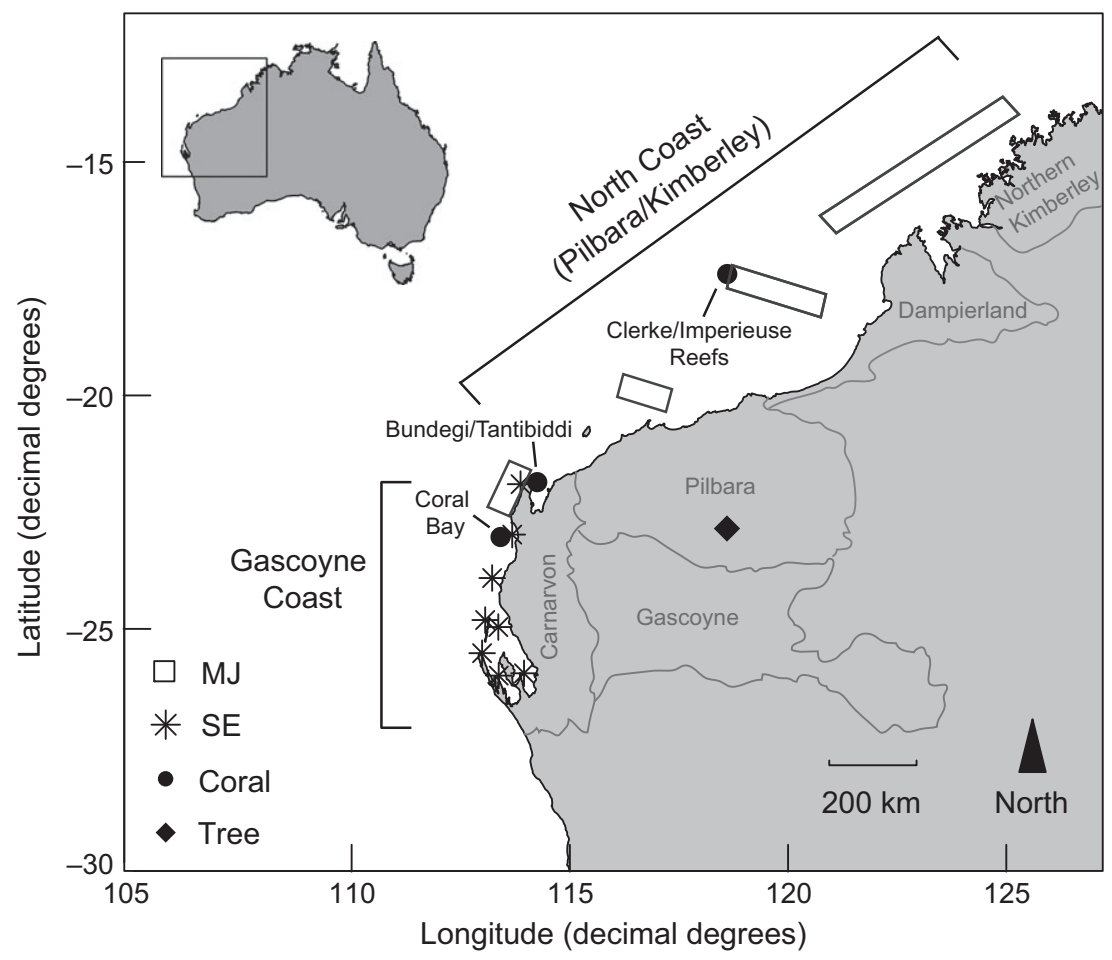

Fig. 1 Sampling locations of growth chronologies for four taxa in northwest Australia. Chronologies were for the period from 1984 to 2003. MJ = mangrove jack (fish; Lutjanus argentimaculatus), SE = spangled emperor (fish; Lethrinus nebulosus), all corals were Porites spp. and trees were Callitris columellaris. Mangrove jack locations are approximate sampling areas within the boxes. Terrestrial regions follow the Interim Biogeographic Regionalization for Australia (IBRA) version 7, modified from the Department of Environment (Australian Government). 
chronologies from all taxa. The quality of the chronologies was assessed using the mean of pair-wise series correlations $(\bar{r})$, an estimate of fractional common variance, and expressed population signal (EPS), a measure of how well the chronology represented the theoretical population chronology (Wigley et al., 1984). These were analyzed using the R package 'dplR' (Bunn, 2008).

Spangled emperor growth chronology. Archived collections of the otoliths of spangled emperor (L. nebulosus) were obtained from the Department of Fisheries (Government of Western Australia). These otoliths came from fish collected in the Gascoyne Coast region of WA (Fig. 1) from 2006 to 2010 (Marriott et al., 2010). The sagittal otoliths of each fish were cleaned and one otolith was embedded in epoxy resin. Two to three thin transverse sections were made near the primordium in a direction perpendicular to the sulcus acusticus with a low speed saw containing a diamond-wafering blade, following the methods of Marriott et al. (2010). The sections were then washed by agitating in $2 \%$ hydrochloric acid for up to $10 \mathrm{~s}$ (to remove calcium build-up), followed by rinsing in water. Dry sections were then mounted on microscope slides using casting resin.

For our analyses, we used the otoliths from 23 fish aged 24 32 years old with sufficiently clear increments for image analysis. The region next to the sulcus acusticus on the dorsal side of each otolith was imaged using an Aperio Scanscope Digital Slide Scanner (Leica Biosystems, Nussloch, Germany) with a motorized stage system. Images were captured using transmitted light with a $20 \times$ objective. Increment widths were measured on the otolith images using a plugin ('IncMeas'; Rountrey, 2009) written for IMAGEJ, an open source image processing program (version 1.48; National Institutes of Health, Bethesda, MD, USA). Two to three transects parallel to the growth axis were drawn, and the outer edge of the opaque zones were marked (along the transects) from the edge of the otolith to the core. The calendar years were also recorded for each marked increment by working backwards from the date of capture and taking into consideration the timing of completion of the opaque zone (austral summer; Marriott et al., 2010), as part of the visual cross-dating process. Cross-dating assumes that the environment induces synchronous, time-specific growth patterns that can be matched among individuals (Fritts, 1971; Gillanders et al., 2012). Averages of increment widths from the multiple transects per sample were calculated and used if the inter-transect correlations were $>0.9$. Statistical cross-dating was used to check the correct assignments of calendar years to increments (Black et al., 2005) and any errors were visually inspected before measurements were changed.

To produce the overall chronology, the increment widths were aligned by fish age and the mean increment width at each age was calculated, following the methods of Black et al. (2013). Each series was then divided by the mean-by-age series to obtain standardized series that removed ontogenetic trends, and the standardized series were averaged by calendar year to create a single overall chronology (see Fig. S1 for raw, detrended, and averaged series). Only years with a sample depth of more than eight fish (1984-2003) were used for analysis. EPS and $\bar{r}$ were calculated using only one time series for each individual fish for the period from 1984 to 2003.
Mangrove jack growth chronology. We used existing detrended (ontogenetic trends removed by dividing the raw series with the mean-by-age series) growth increment series for 36 adult mangrove jack (L. argentimaculatus) that were collected between 1996 and 2005 at various sites along the NW coast (Fig. 1; Ong et al., 2015). The detrended increment series from the 36 fish were averaged to obtain a single growth chronology. The published chronology consisted of increment data from 1975 to 2003 with a sample depth of at least 20 fish contributing to each year value (Ong et al., 2015).

Coral growth chronology. The coral chronology was a record of annual calcification (calculated as the product of linear extension and skeletal density; Lough \& Cooper, 2011) from 24 cores of Porites spp. (Cooper et al., 2012) collected between October 2008 and September 2010 from five reefs (Table S1) along the NW coast (Fig. 1). Data were available from 1900 to 2010. To obtain a standardized growth index, the annual calcification rates were normalized by first subtracting the mean for the period 1961-1990 and subsequently dividing by the standard deviation of this period. Normalized calcification rates were calculated for each of the 24 coral cores from all five reefs. The 24 time series were averaged to obtain a single coral chronology for the NW coast.

Tree-ring chronology. We used a ring-width chronology developed from 27 C. columellaris trees (O'Donnell et al., 2015) from the Hamersley Ranges of the inland Pilbara region (Fig. 1). The chronology had been detrended using the signal free method (Melvin \& Briffa, 2008) to improve the retention of medium frequency (representing time scales of decades to a century) variance, reduce trend distortion at the ends of the chronologies and remove age-related trends ( $\mathrm{O}^{\prime}$ Donnell et al., 2015). The ring-width chronology covered the period 1802 2012 and was constructed using 41 series from the 27 trees.

\section{Climatic and environmental datasets}

Recent studies have shown that ENSO (represented by the Niño-4 index) and SSS are important drivers of the growth of mangrove jack (Ong et al., 2015), while coral growth has been correlated with decadal trends in SST (Cooper et al., 2012). The growth of Callitris trees in the Pilbara mainly responds to rainfall in the austral summer from December to May (Cullen et al., 2008; O'Donnell et al., 2015). We compared growth patterns to the Niño-4 index (based on SST in the Western Pacific between $5^{\circ} \mathrm{N}-5^{\circ} \mathrm{S}$ and $160^{\circ} \mathrm{E}-150^{\circ} \mathrm{W}$; Rayner et al., 2003), SST (HadISST; Rayner et al., 2003), SSS (Good et al., 2013), and rainfall (Jones \& Harris, 2008). All environmental data were obtained from the Royal Netherlands Meteorological Institute (KNMI) Climate Explorer (Trouet \& Van Oldenborgh, 2013), a web application for climate data (http://climexp.knmi.nl). The SST, SSS, and rainfall values were averaged for a grid box covering the NW coast from the Kimberley south to Coral Bay $\left(14^{\circ} \mathrm{S}-28^{\circ} \mathrm{S}, 110^{\circ} \mathrm{E}-127^{\circ} \mathrm{E}\right)$. For each environmental variable, the January to March averages were used because the growing season for fishes, corals, and trees in NW Australia usually occurs in the austral summer (Lough \& Barnes, 2000; 
O'Donnell et al., 2015; Ong et al., 2015 respectively). In addition to the January to March averages for each regional environmental variable from 1984 to 2003, we also used the previous year's values (i.e., 1983-2002) for SST, SSS, and rainfall from the same grid, and for the Niño-4 index to allow for possible lagged responses. Austral winter (June to August) SST values were used in the higher resolution spatial correlation maps detailed below.

\section{Data analyses}

All four chronologies were standardized $\left(\mu=0, \sigma^{2}=1\right)$ and analyzed using principal components analysis (PCA). The scores for the principal components that accounted for the majority of the variance (PC1 and PC2) were tested for significant correlations (using Pearson's correlation) with current and lagged Niño-4 index. The principal component scores were subsequently included as response variables in linear regression models to assess the importance (based on information-theoretic methods) of current year and previous year SST, SSS, and rainfall as drivers of growth. The rainfall values were square root transformed (due to the large range of values from 30 to $200 \mathrm{~mm}$ per month) before insertion into the linear models used in the model selection process, to satisfy the assumptions of homogeneity for linear models. Collinearity between all six environmental variables $(|\mathrm{r}|>0.5, P<0.01)$ was evaluated. The R package 'MUMIN' (Barton, 2015) was used for model selection using the second-order Akaike information criterion (AICc) based on Kullback-Leibler (K-L) information loss and accounting for small sample sizes (Burnham \& Anderson, 2004). Differences in AICc values ( $\triangle \mathrm{AICC}$ ) were used to assess the different models. Adjusted $R^{2}$ values, $F$-statistic, $t$-statistic, and $P$-values were reported. Model validation was carried out to ensure that the models conformed to the assumptions of linear models and tested for auto-correlation. All statistical analyses were completed in R version 3.1.3 (R Development Core Team, 2008). After the model selection process, spatial correlation maps of the significant regional variables were made in the web application KNMI Climate Explorer to show the relationships at a higher spatial resolution.

\section{Results}

\section{Chronology statistics}

The growth chronology of L. nebulosus included the years from 1977 to 2009 (Fig. S1). Measurements from more than eight fish contributed to each yearly value, with 22 out of the 23 fish contributing to the period between 1988 and 2003. Although the fractional common variance $(\bar{r}=0.14)$ and EPS value $(0.78)$ were low relative to tree-ring data, indicating that variability among individuals was high, the mean chronology from 1984 to 2003 did relate to environmental variables as evidenced by significant correlations with January to March SST around the northern Gascoyne Coast $\left(21^{\circ} \mathrm{S}-\right.$ $\left.23^{\circ} \mathrm{S}, 112^{\circ} \mathrm{E}-115^{\circ} \mathrm{E} ; r=0.60, P=0.005\right)$ and marginally significant correlations with average rainfall from January to March over the entire NW area $(r=0.44$, $P=0.05)$.

The published chronology of L. argentimaculatus from 1975 to 2003 had $\bar{r}=0.153$ and EPS $=0.84$ for the entire period (Ong et al., 2015). Bootstrapped $\bar{r}$ and EPS values (Rountrey et al., 2014) were calculated for the 24 coral cores of Porites spp. for all possible 15-year intervals from 1950 to 2003 (Fig. S2) and showed that there was weak but significant synchronicity among corals from the year 1980 onwards ( $\bar{r} \sim 0.05$, EPS $\sim 0.6)$. The published ring-width chronology of $C$. columellaris trees had a running $\bar{r}(>0.4)$ and EPS (>0.85) for 51-year intervals with 25 year overlaps (O'Donnell et al., 2015).

\section{Principal components analysis}

The standardized growth chronologies of all four taxa (Fig. 2, Table S2 shows a correlation matrix) from 1984 to 2003 were analyzed using a PCA. The first principal component (PC1) accounted for $41 \%$ of the variance and PC2 accounted for $33 \%$. The third and fourth principal components each accounted for $<15 \%$ of the variance and were not included in any further analyses. Three of the taxa (fishes and trees) had similar negative loadings on PC1 ( -0.54 to -0.60 ; Table S3), indicating the similarities in growth patterns of these three taxa (Fig. 2a). The coral series had the strongest loading on PC2 (-0.78), followed by L. argentimaculatus ( -0.47 ; Table S3), with Fig. $2 b$ showing the strong synchrony between the coral series and PC2. Inverse values of both PC1 and PC2 were used in further analyses because the strongest loadings were negative as stated above (Table S3).

\section{Relationships with ENSO}

PC1 was negatively correlated with the Niño-4 index (average January to March values) with no lag $(r=-0.65, P=0.002$; Fig. 3a, b). PC2 was negatively correlated with the Niño-4 index (average January to March values) in the previous years $(r=-0.52$, $P=0.02$; Fig. 3c, d).

\section{Relationships with environmental variables}

Because of some collinearity among the six environmental variables $(|\mathrm{r}|>0.5$; Table S4) and the low number of observations $(n=20)$, models using a maximum of two noncollinear variables were constructed. These 17 models (Table S5) were evaluated in the model selection process for PC1 and PC2 separately. The model selection process involving PC1 and the 17 possible combinations of environmental variables found that the 

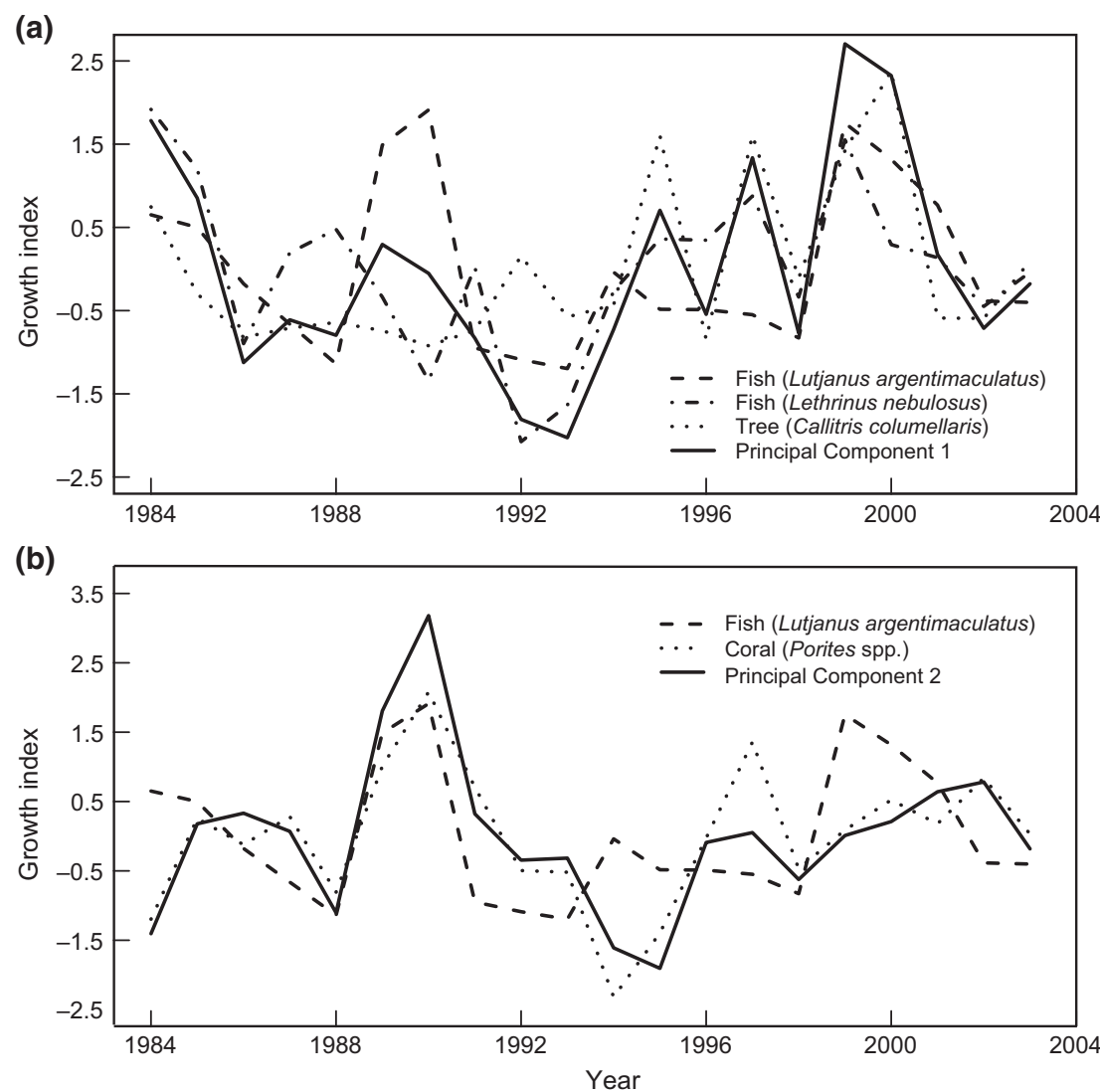

Fig. 2 Growth chronologies of four taxa with the respective leading principal component (PC) scores. Chronologies of four taxa were from northwest Australia and were detrended and normalized (mean $=0$, variance $=1$ ). (a) Mangrove jack (Lutjanus argentimaculatus) chronology, spangled emperor (Lethrinus nebulosus) chronology, and tree-ring width (Callitris columellaris) with PC1and (b) Mangrove jack and coral (Porites spp.) chronology with PC2. The inverse of PC scores was used because the stronger loading taxa were negatively loaded on both PC1 and PC2.

first-ranked model (i.e., lowest AICc) was one that related PC1 with rainfall and SST from the current year (Table 1, Table S5). This first-ranked model was considered to be substantially better than the second model $(\triangle \mathrm{AICc}=8.7$, Table S5). The linear model relating PC1 with rainfall and SST from the current year explained $70 \%$ of the variation in PC1 (Table 1), which largely reflected the growth of fishes and Callitris trees. In this linear model, both variables were highly significant $(P<0.01)$ with rainfall having a positive $t$-value of 4.92 and SST a positive $t$-value of 3.72. Spatial correlation maps (using higher resolution environmental variables) show the positive relationship between PC1 and these two significant variables (Fig. 4a, b).

The second model selection process involving PC2 and the 17 possible combinations of environmental variables identified a first-ranked model that related PC2 with SSS and rainfall from the current year (Table 1, Table S5). This first-ranked model was not considered to be significantly better than the second model that only included SSS $(\triangle \mathrm{AICc}=1.5$, Table S5), hence we chose initially to keep both variables. The linear model relating PC2 with SSS and rainfall from the current year explained $44 \%$ of the variation in PC2 (Table 1), however, SSS was the only significant variable $(t=-4.07, \quad P=0.0008$; Fig. 4c). PC2 (mainly reflecting variation in growth of corals) had a negative relationship with SSS. A spatial correlation map for PC2 and SST from June to August of the previous year (using higher resolution environmental variables) also showed a strong positive relationship between PC2 and offshore waters along the NW coast, in addition to the waters around the Indonesian region (Fig. 4d).

\section{Discussion}

Our study revealed that the growth patterns of taxa from both marine and terrestrial ecosystems in NW Australia were coupled to large-scale, oceanographic, and atmospheric processes. Growth of the study species (two fishes, one coral, and one tree) had significant inverse relationships with the ENSO phenomenon (as 
(a)

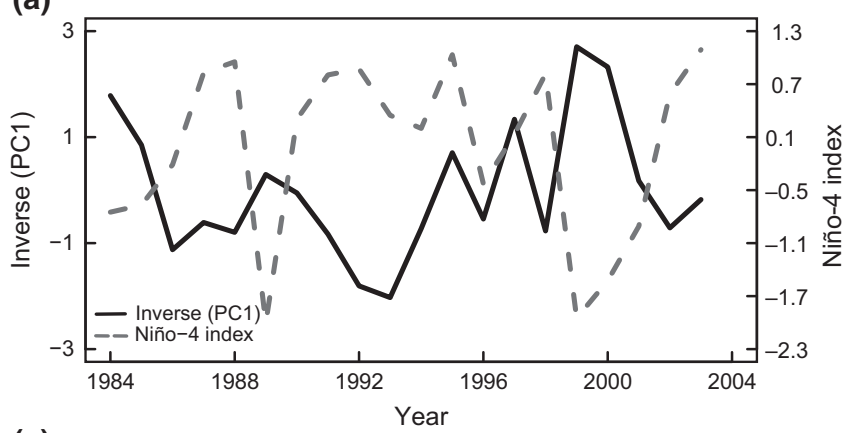

(c)

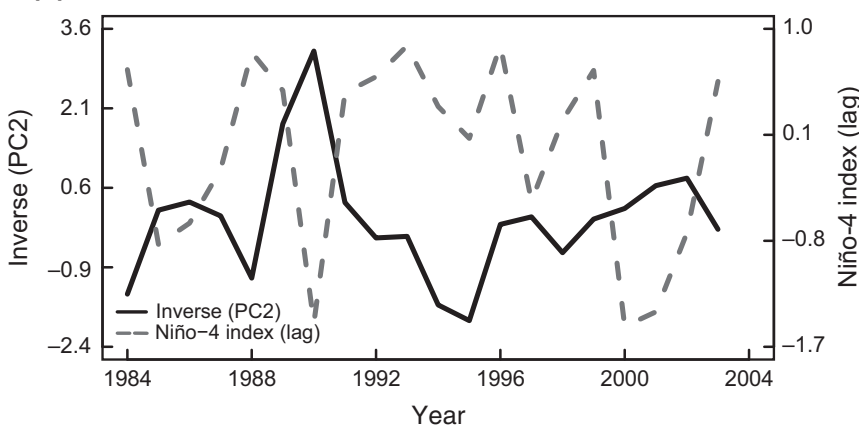

(b)

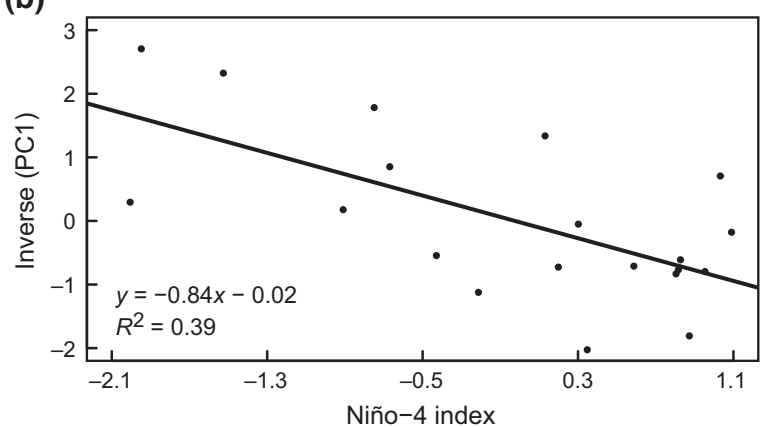

(d)

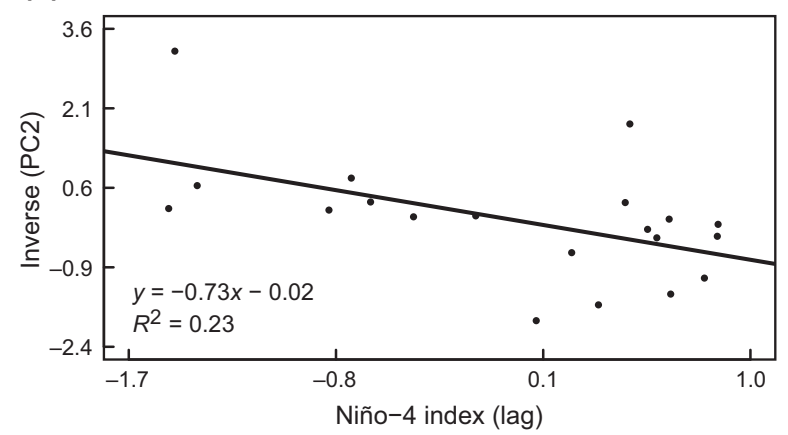

Fig. 3 Relationships between principal component (PC) scores and the Niño-4 index. PC scores were constructed from the growth chronologies of four taxa (two fishes, one coral, and one tree) in northwest Australia and the Niño-4 index was calculated from the average of January to March values. (a) PC1 (mainly reflecting the growth of the two fish and one tree species) and the Niño-4 index over the same years; (b) regression plot of PC1 and the Niño-4 index; (c) PC2 (mainly reflecting the coral chronology) and the lagged Niño-4 index (average January to March values from the previous year), and (d) regression plot of PC2 with lagged Niño-4 index. The inverse of PC scores was used because the stronger loading taxa were negatively loaded on both PC1 and PC2.

Table 1 Selected first-ranked linear models that explain variation in the first two principal component (PC) scores from the growth chronologies of four taxa (two fishes, one coral, and one tree) in northwest Australia. Environmental variables are January to March averages and chronologies are from the years 1984 to 2003.

\begin{tabular}{llll}
\hline Model equation & Adjusted $R^{2}$ & $F$-statistic & $\begin{array}{l}\text { Model } \\
P \text {-value }\end{array}$ \\
\hline PC1 $\sim$ Rainfall + SST & 0.70 & 23.3 & 0.00001 \\
PC2 $\sim$ SSS + Rainfall & 0.44 & 8.4 & 0.003 \\
\hline
\end{tabular}

SST, sea surface temperature; SSS, sea surface salinity.

measured by the Niño-4 index) over two decades, so that when the index was positive (where sustained, strongly positive values indicate an El Niño phase), growth slowed, whereas at times when the index was negative (where sustained, strongly negative values indicate a La Niña phase), growth rates increased.

These strong relationships between ENSO and growth responses of all taxa can be explained by the influence that this phenomenon has on the temperature and salinity of coastal waters and on rainfall patterns in the water-limited terrestrial ecosystems of the NW region. During the La Niña phase of ENSO, there is greater transport of warmer and less saline waters from the western Pacific toward the coast of NW Australia via the Indonesian through-flow (Meyers et al., 2007; Zinke et al., 2014). The stronger Indonesian throughflow subsequently drives a stronger Leeuwin Current that increases the transport of warmer and less saline waters along the coast of WA. Warmer waters have been shown to positively influence growth of fish and corals on the WA coast (Cooper et al., 2012; Rountrey et al., 2014), while lower salinities may increase fish growth through various metabolic pathways that result in reduced metabolic costs (see review by Boeuf \& Payan, 2001) or by increasing food conversion efficiency (Lambert et al., 1994). Furthermore, Hanson et al. (2005) found much higher rates of primary productivity along the coastal Gascoyne region in austral summer, the time when we found strong correlations between the growth of all taxa and ENSO. The Leeuwin Current is weakest during austral summer, when southerly winds that favor coastal upwelling prevail and generate a system of inshore counter-currents that flow toward the Equator (the Ningaloo Current and Capes Current; Hanson et al., 2005). These localized upwelling events 
(a)
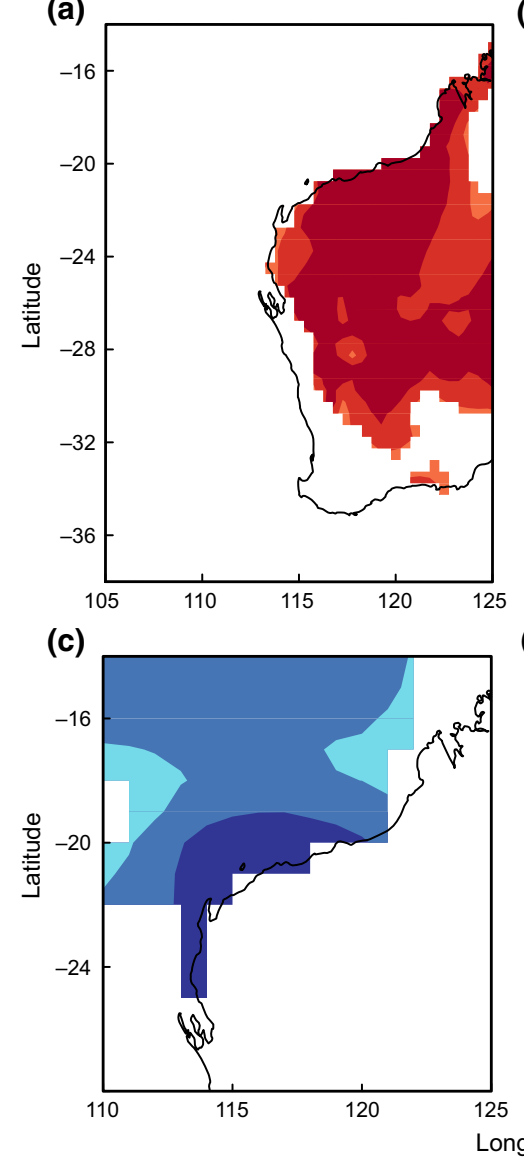

(b)

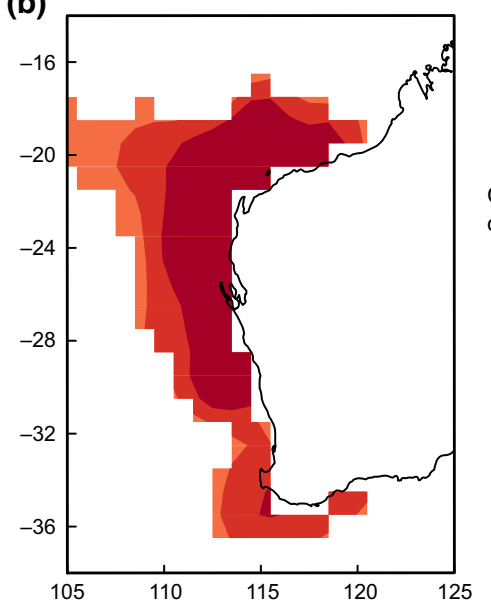

(d)

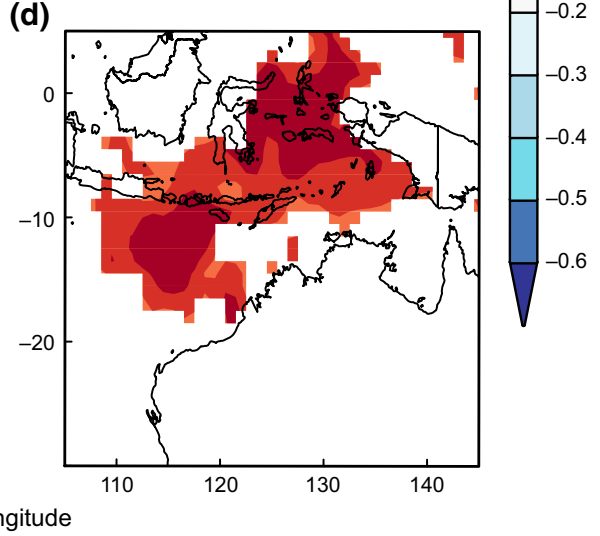

Fig. 4 Significant correlations $(P<0.05)$ between principal component $(\mathrm{PC})$ scores and environmental variables. PC scores were constructed from the growth chronologies of four taxa (two fishes, one coral, and one tree). (a) PC1 and rainfall (mm per month); (b) PC1 and sea surface temperature $\left({ }^{\circ} \mathrm{C}\right.$ ) over the January to March period; (c) PC2 and sea surface salinity (PSU) over the January to March period and (d) PC2 and sea surface temperature $\left({ }^{\circ} \mathrm{C}\right)$ from June to August in the previous year. All data were from the years 1984 to 2003 and PC scores were plotted on an inverted scale because the strongest loading taxa were negatively loaded on both PC 1 and PC2. Maps were obtained and modified from KNMI Climate Explorer.

enhance primary production in otherwise oligotrophic waters and might play an important role in the increased growth of our study organisms that we observed during the austral summer.

The La Niña phase of ENSO is also typically associated with higher rainfall over inland northwest Australia. La Niña tends to strengthen the Australian monsoon by influencing SSTs, low-level winds, vertical motion, and convection north of Australia (Wang et al., 2003). This enhanced monsoon causes higher rainfall over northwest (and much of northern and eastern) Australia, which in turn stimulates tree growth in northwest Australia (Cullen et al., 2008; O'Donnell et al., 2015). The ENSO phenomenon also influences northwest Australian rainfall through its effect on the activity of tropical cyclones off the northwest coast of Australia (Denniston et al., 2015), where tropical cyclone activity is enhanced in La Niña and suppressed in El Niño conditions (Liu \& Chan, 2012). Tropical cyclones (and other closed low pressure systems) cause intense rain events over inland northwest Australia and contribute to more than half of the region's annual rainfall (Lavender \& Abbs, 2013). Along the North Coast where there is higher rainfall, it is possible for river outflows to directly link terrestrial and marine systems, however, our tree and some fish data were mostly collected around the Gascoyne region, an area subject to very sporadic patterns of rainfall and river outflow (Lough, 1998). Hence, it is more likely that the La Niña phase of ENSO positively influences the growth of both fishes and trees in NW Australia, due to its indirect links with climatic conditions likely to favor growth (i.e., warmer, less saline sea water in the eastern Indian Ocean, and greater rainfall over northwest Australia).

The correlations between ENSO and growth patterns of our study species occurred despite the fact that the 
fractional common variance of the growth chronology of L. nebulosus was relatively low compared to trees and some fishes (e.g., Cullen \& Grierson, 2007; Gillanders et al., 2012). Such low common variances appear to be a feature of fishes sampled from the WA coast (e.g., Rountrey et al., 2014; Nguyen et al., 2015; Ong et al., 2015), but it is important to note that all WA fishes for which growth chronologies have been constructed have displayed significant correlations with regional environmental factors such as SST.

The strong correlations that we found between PC2 (largely reflecting coral growth) and SSS were unexpected, given the small range of changes in salinity that occur in the NW region and the results of an earlier study that suggested that decadal growth rates of corals were most strongly correlated with SST (Cooper et al., 2012). However, we found a strong collinearity between SSS and lagged SST at higher spatial resolution scales, implying that the latter (or perhaps some other unmeasured factor) may be causing the apparent correlation between SSS and coral growth. Our results also showed that SST from June to August in the previous year had strong positive correlations with PC2. The lag in this relationship may reflect the fact that coral calcification values were based on a year defined by annual density minima, which were presumed to occur in the austral winter months of June to August (Cantin \& Lough, 2014). Hence, a year in the coral chronology was based on calcification rates from August of the previous calendar year to August of the current calendar year. Alternatively, changes in salinity, in particular anomalous lows, were responsible for around 30\% of the unusual enhancement of the Leeuwin Current transport during the marine heatwave event in the austral summer of 2010/2011 (Feng et al., 2015). This observation suggests that salinity may have a more general influence on the growth rates of marine taxa in the NW region.

The importance of ENSO along the coastline of WA is well recognized. In this region, the interannual variability of this phenomenon has been linked to the survival of various life history stages of marine taxa, with La Niña years (stronger Leeuwin Current) showing a greater transport of nutrients into the euphotic zone (Thompson et al., 2011) that accounts for greater phytoplankton biomass (Koslow et al., 2008) and increased fisheries recruitment (Caputi, 2008). Our findings show the influence of ENSO on the growth rates of adult fish and corals, increasing our knowledge of the far-reaching impacts of ENSO on a range of life history stages of marine taxa and across different trophic levels. In addition to strong correlations between growth of all taxa and the current year's ENSO, we also found significant, albeit slightly weaker, correlations between growth and the ENSO signal in the previous year. This suggests that the influence of the ENSO system on growth may carry over between years.

Overall, the strong negative relationship between the growth responses of all four taxa with ENSO has important implications for the future. Predicted increases in rainfall (Christensen et al., 2013) and SST (Cheung et al., 2012) for NW Australia suggest that growth rates of our study taxa will continue to increase in WA until thermal limits are reached. However, the strong La Niña conditions (with peak SST reaching $5{ }^{\circ} \mathrm{C}$ above average) over the summer of 2011 led to fish kills and widespread coral bleaching (Feng et al., 2013), suggesting that the thermal limits of fishes and corals are relatively close to present day conditions on the NW coast. Extreme La Niña events typically follow strong El Niño conditions and both are predicted to occur more frequently in the future (Cai et al., 2014, 2015), which may create greater year-to-year variation in the productivity and yield of fisheries and the likelihood of bleaching in coral communities along the NW coast. The magnitude of SST changes in the future (along with the frequencies of El Niño and La Niña events) is likely to have major consequences on both marine and terrestrial taxa and will need to be carefully monitored.

The similarities in the growth patterns of the fish and tree species used in this study suggest that it may be possible to use tree-ring chronologies to hindcast/reconstruct the growth responses of fish where archives of otoliths do not exist. In many coastal locations worldwide, tree-ring chronologies now extend centuries into the past, while the most comprehensive otolith archives are generally the product of fisheries management studies with a relatively recent history ( $<60$ years in most cases). Our study shows that where strong links between the growth of fishes and trees can be established, chronologies of tree growth may provide a proxy to understand the response of fish populations to climate change, both in the past and the future.

In summary, we have provided the first empirical evidence for climate-driven synchrony between marine and terrestrial ecosystems in the Southern Hemisphere at annual time scales. These links occur through the influence of ENSO events on regional environmental variables that affect the annual growth of fishes, corals, and trees throughout the region. Although we lacked an overlap of all taxonomic groups across the entire region, this is a common limitation of any program that seeks to access legacy datasets where researchers had no control over the intensity and location of sampling in the past. The large historical archives of fish otoliths (Campana \& Thorrold, 2001), coral (e.g., Tierney et al., 2015) and tree-ring (St. George, 2014) records held by 
institutions and organizations worldwide offer a major opportunity to expand the scale and resolution of our approach. This will improve both our understanding of the effect of climate fluctuations on ecosystems in the past and the likely impact of climate change on both marine and terrestrial ecosystems in the future.

\section{Acknowledgements}

This work was funded by the Australian National Network in Marine Science and the Australian Institute of Marine Science. JJLO was supported by a scholarship from the Australian Postgraduate Awards. JZ was supported by a UWA/AIMS/CSIRO fellowship and a Curtin Senior Research Fellowship. The authors acknowledge the facilities, and the scientific and technical assistance of the Australian Microscopy \& Microanalysis Research Facility at the Center for Microscopy, Characterization \& Analysis, the University of Western Australia, a facility funded by the University, State and Commonwealth Governments. In particular, we would like to thank Professor Paul Rigby and Miss Alysia Buckley for the help and advice they have provided.

\section{References}

Barton K (2015) Multi-model Inference. R package version 1.13.4. Available at: http://CRAN.R-project.org/package=MuMIn (accessed 17 April 2015).

Black BA, Boehlert GW, Yoklavich MM (2005) Using tree-ring crossdating techniques to validate annual growth increments in long-lived fishes. Canadian Journal of Fisheries and Aquatic Sciences, 62, 2277-2284.

Black BA, Copenheaver CA, Frank DC, Stuckey MJ, Kormanyos RE (2009) Multiproxy reconstructions of northeastern Pacific sea surface temperature data from trees and Pacific geoduck. Palaeogeography, Palaeoclimatology, Palaeoecology, 278, 4047.

Black BA, Matta ME, Helser TE, Wilderbuer TK (2013) Otolith biochronologies as multidecadal indicators of body size anomalies in yellowfin sole (Limanda aspera). Fisheries Oceanography, 22, 523-532.

Black BA, Sydeman WJ, Frank DC et al. (2014) Six centuries of variability and extremes in a coupled marine-terrestrial ecosystem. Science, 345, 1498-1502.

Boeuf G, Payan P (2001) How should salinity influence fish growth? Comparative Biochemistry and Physiology Part C, 130, 411-423.

Braganza K, Gergis JL, Power SB, Risbey JS, Fowler AM (2009) A multiproxy index of the El Niño-Southern Oscillation, A.D. 1525-1982. Journal of Geophysical Research: Atmospheres, 114, D05106.

Bunn AG (2008) A dendrochronology program library in R (dplR). Dendrochronologia, 26, 115-124.

Burnham KP, Anderson DR (2004) Multimodel inference: understanding AIC and BIC in model selection. Sociological Methods \& Research, 33, 261-304.

Cai W, Borlace S, Lengaigne M et al. (2014) Increasing frequency of extreme El Niño events due to greenhouse warming. Nature Climate Change, 4, 111-116.

Cai W, Wang G, Santoso A et al. (2015) Increasing frequency of extreme La Niña events under greenhouse warming. Nature Climate Change, 5, 132-137.

Campana SE, Thorrold SR (2001) Otoliths, increments, and elements: keys to a comprehensive understanding of fish populations? Canadian Journal of Fisheries and Aquatic Sciences, 58, 30-38.

Cantin NE, Lough JM (2014) Surviving coral bleaching events: Porites growth anomalies on the Great Barrier Reef. PLoS One, 9, e88720.

Caputi N (2008) Impact of the Leeuwin Current on the spatial distribution of the puerulus settlement of the western rock lobster (Panulirus cygnus) and implications for the fishery of Western Australia. Fisheries Oceanography, 17, 147-152.

Cheung WWL, Meeuwig JJ, Feng M et al. (2012) Climate-change induced tropicalization of marine communities in Western Australia. Marine and Freshwater Research, 63,415 .

Christensen JH, Krishna Kumar K, Aldrian E et al. (2013) Climate phenomena and their relevance for future regional climate change. In: Climate Change 2013: The Physical Science Basis (eds Stocker TF, Qin D, Plattner G-K, Tignor M, Allen SK,
Boschung J, Nauels A, Xia Y, Bex V, Midgley PM), pp. 1217-1308. Cambridge University Press, Cambridge, UK and New York, NY, USA.

Cooper TF, O'Leary RA, Lough JM (2012) Growth of Western Australian corals in the Anthropocene. Science, 335, 593-596.

Cresswell GR, Golding TJ (1980) Observations of a southward flowing current in the south-eastern Indian Ocean. Deep-Sea Research, 27A, 449-466.

Cullen LE, Grierson PF (2007) A stable oxygen, but not carbon, isotope chronology of Callitris columellaris reflects recent climate change in north-western Australia. Climatic Change, 85, 213-229.

Cullen LE, Grierson PF (2009) Multi-decadal scale variability in autumn-winter rainfall in south-western Australia since $1655 \mathrm{AD}$ as reconstructed from tree rings of Callitris columellaris. Climate Dynamics, 33, 433-444.

Cullen LE, Adams MA, Anderson MJ, Grierson PF (2008) Analyses of $\delta 13 \mathrm{C}$ and $\delta 18 \mathrm{O}$ in tree rings of Callitris columellaris provide evidence of a change in stomatal control of photosynthesis in response to regional changes in climate. Tree Physiology, 28, 1525-1533.

Dai A, Wigley TML (2000) Global patterns of ENSO-induced precipitation. Geophysical Research Letters, 27, 1283-1286.

Denniston RF, Villarini G, Gonzales AN et al. (2015) Extreme rainfall activity in the Australian tropics reflects changes in the El Niño/Southern Oscillation over the last two millennia. Proceedings of the National Academy of Sciences, 112, 4576-4581.

Feng M, Waite AM, Thompson PA (2009) Climate variability and ocean production in the Leeuwin Current system off the west coast of Western Australia. Journal of the Royal Society of Western Australia, 92, 67-81.

Feng M, McPhaden MJ, Xie SP, Hafner J (2013) La Niña forces unprecedented Leeuwin Current warming in 2011. Scientific Reports, 3, 1277.

Feng M, Benthuysen J, Zhang N, Slawinski D (2015) Freshening anomalies in the Indonesian throughflow and impacts on the Leeuwin Current during 2010-2011. Geophysical Research Letters, 42, 8555-8562.

Fletcher WJ, Santoro K (2014) Status reports of the Fisheries and Aquatic resources of Western Australia 2013/14: The state of the Fisheries. Department of Fisheries, Western Australia.

Fritts HC (1971) Dendroclimatology and dendroecology. Quaternary Research, 1, 419 449.

Gentilli J (1971) Climate of Australia and New Zealand. Elsevier, Amsterdam.

Gillanders BM, Black BA, Meekan MG, Morrison MA (2012) Climatic effects on the growth of a temperate reef fish from the Southern Hemisphere: a biochronological approach. Marine Biology, 159, 1327-1333.

Good SA, Martin MJ, Rayner NA (2013) EN4: Quality controlled ocean temperature and salinity profiles and monthly objective analyses with uncertainty estimates. Journal of Geophysical Research, 118, 6704-6716.

Guyette RP, Rabeni CF (1995) Climate response among growth increments of fish and trees. Oecologia, 104, 272-279.

Hanson CE, Pattiaratchi CB, Waite AM (2005) Sporadic upwelling on a downwelling coast: Phytoplankton responses to spatially variable nutrient dynamics off the Gascoyne region of Western Australia. Continental Shelf Research, 25, 1561-1582.

Hendy EJ, Gagan MK, Alibert CA, McCulloch MT, Lough JM, Isdale PJ (2002) Abrupt decrease in tropical pacific sea surface salinity at end of little ice age. Science, 295, 1511-1514.

Hoegh-Guldberg O, Bruno JF (2010) The impact of climate change on the world's marine ecosystems. Science, 328, 1523-1528.

Jones PD, Harris I (2008) Climatic Research Unit (CRU) time-series datasets of variations in climate with variations in other phenomena. University of East Anglia Climatic Research Unit, NCAS British Atmospheric Data Centre, Harwell, Oxford, UK.

Koslow JA, Pesant S, Feng M et al. (2008) The effect of the Leeuwin Current on phytoplankton biomass and production off Southwestern Australia. Journal of Geophysical Research: Oceans, 113, C07050.

Lambert Y, Dutil J-D, Munro J (1994) Effects of intermediate and low salinity conditions on growth rate and food conversion of Atlantic cod (Gadus morhua). Canadian Journal of Fisheries and Aquatic Sciences, 51, 1569-1576.

Lavender SL, Abbs DJ (2013) Trends in Australian rainfall: contribution of tropical cyclones and closed lows. Climate Dynamics, 40, 317-326.

Liu KS, Chan JCL (2012) Interannual variation of Southern Hemisphere tropical cyclone activity and seasonal forecast of tropical cyclone number in the Australian region. International Journal of Climatology, 32, 190-202.

Lough JM (1998) Coastal climate of northwest Australia and comparisons with the Great Barrier Reef: 1960 to 1992. Coral Reefs, 17, 351-367.

Lough JM (2011) Great Barrier Reef coral luminescence reveals rainfall variability over northeastern Australia since the 17th century. Paleoceanography, 26, PA2201.

Lough JM, Barnes DJ (2000) Environmental controls on growth of the massive coral Porites. Journal of Experimental Marine Biology and Ecology, 245, 225-243. 
Lough JM, Cooper TF (2011) New insights from coral growth band studies in an era of rapid environmental change. Earth-Science Reviews, 108, 170-184.

Marriott RJ, Adams DJ, Jarvis NDC, Moran MJ, Newman SJ, Craine M (2010) Agebased demographic assessment of fished stocks of Lethrinus nebulosus in the Gascoyne Bioregion of Western Australia. Fisheries Management and Ecology, 18, 89-103.

Marshall A, Hendon H, Feng M, Schiller A (2015) Initiation and amplification of the Ningaloo Niño. Climate Dynamics, 45, 2367-2385

Melvin TM, Briffa KR (2008) A "signal-free" approach to dendroclimatic standardization. Dendrochronologia, 26, 71-86.

Meyers G (1996) Variation of Indonesian throughflow and the El Niño-Southern Oscillation. Journal of Geophysical Research, 101, 12255.

Meyers G, McIntosh P, Pigot L, Pook M (2007) The Years of El Niño, La Niña, and Interactions with the Tropical Indian Ocean. Journal of Climate, 20, 2872-2880.

Morrongiello JR, Thresher RE, Smith DC (2012) Aquatic biochronologies and climate change. Nature Climate Change, 2, 849-857.

Nguyen HM, Rountrey AN, Meeuwig JJ et al. (2015) Growth of a deep-water, predatory fish is influenced by the productivity of a boundary current system. Scientific Reports, 5, 9044

O'Donnell AJ, Cook ER, Palmer JG, Turney CSM, Page GFM, Grierson PF (2015) Tree rings show recent high summer-autumn precipitation in Northwest Australia is unprecedented within the last two centuries. PLoS One, 10, e0128533.

Ong JJL, Rountrey AN, Meeuwig JJ, Newman SJ, Zinke J, Meekan MG (2015) Contrasting environmental drivers of adult and juvenile growth in a marine fish: implications for the effects of climate change. Scientific Reports, 5, 10859.

Pearce A, Feng M (2007) Observations of warming on the Western Australian continental shelf. Marine and Freshwater Research, 58, 914-920.

R Development Core Team (2008) R: A Language and Environment for Statistical Computing 3.1.3. Available at: http://www.R-project.org/ (accessed 1 June 2013).

Rayner NA, Parker DE, Horton EB et al. (2003) Global analyses of sea surface temperature, sea ice, and night marine air temperature since the late nineteenth century. Journal of Geophysical Research, 108, 4407.

Richardson AJ, Brown CI, Brander K et al. (2012) Climate change and marine life. Biology Letters, 8, 907-909.

Rosenzweig C, Karoly D, Vicarelli M et al. (2008) Attributing physical and biological impacts to anthropogenic climate change. Nature, 453, 353-357.

Rountrey AN (2009) Life histories of juvenile woolly mammoths from Siberia: stable isotope and elemental analyses of tooth dentin. PhD Thesis. The University of Michigan, USA.

Rountrey AN, Coulson PG, Meeuwig JJ, Meekan MG (2014) Water temperature and fish growth: otoliths predict growth patterns of a marine fish in a changing climate. Global Change Biology, 20, 2450-2458.

St. George SR (2014) The global network of tree-ring widths and its applications to paleoclimatology. PAGES Magazine, 22, 16-17.
Thompson PA, Wild-Allen K, Lourey M, Rousseaux C, Waite AM, Feng M, Beckley LE (2011) Nutrients in an oligotrophic boundary current: evidence of a new role for the Leeuwin Current. Progress in Oceanography, 91, 345-359.

Tierney JE, Abram NJ, Anchukaitis KJ et al. (2015) Tropical sea surface temperatures for the past four centuries reconstructed from coral archives. Paleoceanography, 30, 226-252.

Trouet V, Van Oldenborgh GJ (2013) KNMI Climate Explorer: a web-based research tool for high-resolution paleoclimatology. Tree-ring Research, 69, 3-13.

Wang B, Wu R, Li T (2003) Atmosphere-warm ocean interaction and its impacts on Asian-Australian monsoon variation. Journal of Climate, 16, 1195-1211.

Wigley TML, Briffa KR, Jones PD (1984) On the average value of correlated time series, with applications in dendroclimatology and hydrometeorology. Journal of Climate and Applied Meteorology, 23, 201-213.

Zinke J, Rountrey AN, Feng M et al. (2014) Corals record long-term Leeuwin current variability including Ningaloo Niño/Niña since 1795 . Nature Communications, 5, 3607.

Zinke J, Hoell A, Lough JM et al. (2015) Coral record of southeast Indian Ocean marine heatwaves with intensified Western Pacific temperature gradient. Nature Communications, 6 , 8562

\section{Supporting Information}

Additional Supporting Information may be found in the online version of this article:

Figure S1. Raw and detrended increment width time series for Lethrinus nebulosus.

Figure S2. Assessment of chronology properties for the 24 Porites spp. cores.

Table S1. Growth chronologies of fishes, corals, and trees.

Table S2. Correlation matrix of the growth chronologies of the four taxa.

Table S3. Loadings of the four taxa on the principal components.

Table S4. Correlation matrix of the six environmental variables.

Table S5. Selected models in the model selection process. 